Çukurova Üniversitesi Mühendislik Mimarlık Fakültesi Dergisi, 34(2), ss. 9-22, Haziran 2019

Çukurova University Journal of the Faculty of Engineering and Architecture, 34(2), pp. 9-22, June 2019

\title{
Adana ve Mersin'de Bulunan Etlik Piliç Kümeslerinde Oluşan Gübrenin Biyogaz ve Elektrik Üretim Potansiyelinin Belirlenmesi
}

\author{
Metin DAĞTEKİN*1, Ali AYBEK², M. Emin BİLGÍLí ${ }^{3}$ \\ ${ }^{1}$ Çukurova Üniversitesi Ceyhan Meslek Yüksekokulu, Ceyhan, Adana \\ ${ }^{2}$ Kahramanmaraş Sütçü Imam Üniversitesi, Ziraat Fakültesi, Biyosistem Mühendisliği Bölümü, \\ Kahramanmaraş \\ ${ }^{3}$ Doğu Akdeniz Tarımsal Araştırma Enstitüsü Müdürlüğ̈̈, Adana
}

Geliş tarihi: 07.01.2019

Kabul tarihi: 28.06.2019

Öz

Bu çalışmanın amacı, Adana ve Mersin'de bulunan etlik piliç (broiler) işletmelerinde oluşan gübrelerin biyogaz enerji potansiyelini belirlemek ve konuya ilişkin yerel ölçekte sürdürülebilir çözümler oluşturmaktır. Çalışmada ayrıca ilçeler bazında biyogaz enerji değerlerinin yersel değişim haritalarının oluşturulması ve bölgede aile tipi biyogaz tesisinin kurulmasının elektrik üretimine katkısı da irdelenmiştir. Çalışmada, Mersin ilinin etlik piliç gübresinden yıllık üretilebilecek biyogaz metan potansiyeli $70.679 .580,90 \mathrm{~m}^{3}$, 1s1 enerji miktarı $25.911,13 \mathrm{GJ}$ ve elektrik enerji miktar1 2.879,01 $\mathrm{MW}_{\text {he }}$ olarak hesaplanmıştır. Bu değerler Adana İli'nde ise sırası ile 32.080.138,64 m³ $, 11.760,58$ GJ ve $1.306,73 \mathrm{MW}_{\text {he }}$ olarak tespit edilmiştir. İlçeler bazında etlik piliç gübresinden yıllık elektrik enerjisi üretimi; Mersin İli için en yüksek değer Tarsus İlçesi'nde (2.093,29 $\left.\mathrm{MW}_{\text {he }}\right)$ belirlenmiştir. Bunu sırası ile Akdeniz (284,74 $\mathrm{MW}_{\text {he }}$ ) ve Çamliyayla (151,83 $\mathrm{MW}_{\text {he) }}$ izlemiştir. Adana'da ise, en yüksek değer Ceyhan (327,84 $\left.\mathrm{MW}_{\mathrm{he}}\right)$ ilçesinde belirlenmiştir. Bunu sırası ile Yüreğir $\left(280,21 \mathrm{MW}_{\mathrm{he}}\right)$, Seyhan $\left(273,06 \mathrm{MW}_{\mathrm{he}}\right)$, Sarıçam $\left(132,99 \mathrm{MW}_{\text {he }}\right)$ ve Karaisalı $\left(128,87 \mathrm{MW}_{\text {he }}\right)$ izlemiştir. Çalışma sonucunda, söz konusu bu ilçelerde biyogaz tesislerinin kurulması için uygun potansiyelin olduğu tespit edilmiştir. Kurulacak biyogaz tesislerinin kümeslerde aydınlatma, 1sıtma, su ve yem dağıtımında kullanılan elektrik motorlarının ve işletmedeki ailelerin elektrik ihtiyacını karşılayabileceği belirlenmiştir. Ayrıca, kurulacak biyogaz tesislerinin bölgede metan gazının çevreye verdiği zararları önleyebilecek fermente edilmiş ve gazı alınmış hayvansal gübrelerin organik gübre olarak işletmelere bir ticari değer katkısı da sağlayabilecektir.

Anahtar kelimeler: Biyogaz, Etlik piliç, Gübre, Elektrik enerjisi

\section{Evaluation of Biogas and Electricity Production Potential of Fertilizer in Broiler Poultry Houses in Adana and Mersin}

\begin{abstract}
The aim of this study is to determine the biogas energy potential of fertilizers in broiler poultry houses located in Adana and Mersin and to create sustainable solutions on a local scale. In the study, the creation of local change maps of biogas energy values on the basis of districts and the contribution of the
\end{abstract}

*Sorumlu yazar (Corresponding author): Metin DAĞTEKIN, mmdagtekin@gmail.com 
establishment of family type biogas plant in the region to electricity production were also examined. In the study, the biogas methane potential of Mersin province which is produced from broiler fertilizer is calculated as $70,679,580.90 \mathrm{~m}^{3}$, the heat energy amount is $25,911.13 \mathrm{GJ}$ and the electrical energy amount is 2,879.01 MWhe. These values were determined as 32,080,138.64 $\mathrm{m}^{3}, 11,760.58 \mathrm{GJ}$ and $1,306.73 \mathrm{MW}_{\text {he }}$ in Adana province, respectively. Annual electricity production from broiler manure based on districts; The highest value for the province of Mersin (2,093.29 $\left.\mathrm{MW}_{\mathrm{he}}\right)$ was determined in the district of Tarsus. It was followed by Akdeniz (284.74 $\mathrm{MW}_{\mathrm{he}}$ ), and Çamliyayla (151.83 $\mathrm{MW}_{\mathrm{he}}$ ), respectively. In Adana, the highest value was determined in Ceyhan (327.84 $\mathrm{MW}_{\text {he }}$ ). This was followed by Yüregir (280.21 $\mathrm{MW}_{\mathrm{he}}$ ), Seyhan (273.06 $\mathrm{MW}_{\mathrm{he}}$ ), Sarıçam (132.99 $\mathrm{MW}_{\text {he }}$ ) and Karaisalı (128.87 $\mathrm{MW}_{\mathrm{he}}$ ). As a result of this study, it has been determined that there is a potential for the establishment of biogas plants in these districts. It is determined that the biogas plants to be installed can meet the electricity needs of electric motors and families in operation in lighting, heating, water and feed distribution in the poultry houses. In addition, it will be able to provide a commercial value contribution to the enterprises of fermented and degassed animal fertilizers as organic fertilizers which can prevent the environmental damage of methane gas in the region.

Key words: Biogas, Broiler, Fertilizer, Electrical energy

\section{GİRIȘ}

Dünya nüfusunun hızla artması ve gelişen sanayileşmeyle birlikte, enerji kaynakları kullanımı önemli seviyelere ulaşmıştır. Fosil kökenli yakıtlar dünyanın enerji arzında büyük paya sahiptir ve mevcut çevresel sorunlara, özellikle hava kirliliği ve küresel ısınmaya neden olmaktadır. Buna göre, kaynakların hızlı tükenmesi ve fiyat dalgalanmaları, dünya genelinde yenilebilir enerji kaynakları eğiliminde bir artışa neden olmuştur [1,2].

Ülkemiz enerji kaynakları bakımından sınırlı sayıda rezervlere sahiptir ve enerji kullanımının yaklaşık \%60'ını dışarıdan ithal etmektedir. Fakat ülkemiz yenilenebilir enerji kaynakları açısından oldukça zengin olup, yeterince değerlendirilmemektedir [3,4]. Yenilenebilir enerji kaynakları içerisinde yer alan biyokütle enerji kaynaklarından elde edilen yakıtlardan biri de biyogazdır. Çevresel ve sağlık sorunlarına yol açan organik atıkların işlenerek zararsız hale getirilmesi ve bu atıkların enerjiye dönüştürülmesini sağlayan biyogaz teknolojisi yenilenebilir enerji üretiminde en ön sırada yer almaktadır. Biyogaz, organik bazlı atıkların oksijensiz ortamda (anaerobik) fermantasyonu sonucu ortaya çıkan renksiz, kokusuz, havadan hafif, parlak mavi bir alevle yanan ve bileşiminde yaklaşık olarak \%55-75 metan, \%24-44 karbondioksit ve çok az miktarlarda hidrojen sülfür, azot, karbon monoksit, oksijen ve hidrojen bulunan bir gaz karışımdır [5-7]. Biyogaz doğal gaza alternatif bir gaz yakıt olarak doğrudan yakma-1sınma ve isitmada, motor ve türbin yakıtı olarak, elektrik enerjisi elde edilmesinde, yakıt pili yakıtı olarak, doğal gaz içine katkı olarak ve kimyasalların üretiminde kullanılmaktadır.

Ülkemizde hayvan potansiyelinin, tarımsal alanların, hayvancılık ve tarımla uğraşan nüfusun fazla olmasından dolayı biyogaz, ülkemiz için etkili bir enerji kaynağı potansiyelini taşımaktadır $[2,8]$. Ülkemizin yıllık ve toplam geri kazanılabilir biyokütle enerji potansiyeli sırasıyla 32,6 ve 17,2 MTEP (Milyon Ton Eşdeğer Petrol) olarak tahmin edilmektedir. $\mathrm{Bu}$ enerji potansiyeli içerisinde hayvancılıktan yaklaşık 72 milyon ton yıllık hayvan gübresi tahmini yapılmaktadır [9].

Hayvan gübresinin büyük bir bölümünün doğrudan kırsal alanlarda 1sitma amaciyla kontrolsüz depolanması veya yakılması, gübrenin kalitesinde azalmaya, enerjinin çoğunun kaybına, koku ve görsel sorunlara, toprak ve su kirliliği gibi çeşitli çevre ve sağlık sorunlarına da neden olmaktadır [10]

Etlik piliç (broiler) gübresinden biyogaz ve elektrik enerjisi üretimi ile söz konusu gübrelerin 
çevresel sorunlarının çözümüne yönelik önemli bir alternatiftir. Ülkemizde yıllık etlik piliç üretimi 221 milyon adete ulaşmış olup, bu rakamın yaklaşık 23 milyon adeti Adana ve Mersin illerinde yetiştirilmektedir [11]. Bu rakam biyogaz enerji üretimi için kullanılan kümes atıklarının bölgede ne denli yüksek potansiyele sahip olduğunu göstermektedir. Ayrıca bölgede bu atıkların uygun bir şekilde bertaraf edilmesi çevre güvenliği açısından da önem taşımaktadır.

Adana ve Mersin illerinde etlik piliç üretimi kırsal kesimde yapılmakta ve bölgedeki üreticilerin büyük çoğunluğunu aile tipi işletmeler oluşturmaktadır. Bölgede yılda genellikle 5 dönemde yapılmakta olan yetiştiricilik; kümesin fiziki koşulu, bölgenin iklimsel özelliği ve işletmenin ekonomik yapısına bağlı olarak 6 döneme de çıkabilmektedir.

Kümeslere ait atık çukuru veya buna benzer güvenli muhafaza yeri olmadığından dolayı üreticiler, oluşan atıkları kümesin temizlenmesi karşılığında veya çok düşük bir ücretle değerlendirmektedirler. Yüksek enerji üretim potansiyeline sahip olan bu hayvansal atıkların değerlendirilmeden bertaraf edilmesi milli enerji kaynaklarımız için önemli bir kayıptır. Bölge koşullarına ve işletmenin üretim kapasitesine uygun tipte biyogaz tesisinin yapılıp, bölgede yaygınlaştırılmasının çevresel kirliliğin korunması yanında, kırsal kesimdeki üreticilerin sosyoekonomik ve kültürel açıdan gelişmesine de önemli katkıları bulunacaktır.

$\mathrm{Bu}$ çalışmanın amacı, Adana ve Mersin illerine bağlı bulunan etlik piliç işletmelerinde oluşan gübrelerin biyogaz enerji potansiyelini belirlemek ve konuya ilişkin yerel ölçekte sürdürülebilir çözümler oluşturmaktır. Ayrıca, bu çalışmada ilçeler bazında biyogaz enerji değerlerinin yersel değişim haritalarının oluşturulması ve bölgede yoğun üretim yapılan kümesler için aile tipi biyogaz tesislerinin kurulmasının elektrik üretimine katkısı da irdelenmiştir.

\section{MATERYAL VE YÖNTEM}

\subsection{Materyal}

Çalışmada, Adana ve Mersin illerine bağlı bulunan etlik piliç işletmelerinin biyogaz enerji potansiyelinin belirlenmesi için gerekli hayvan sayıları, İl Tarım ve Orman Müdürlüğü, Hayvan Sağlığı ve Yetiştiriciliği Şube Müdürlügünün 2018 yılı kayıtlarından alınmıştır. Adana İli 14 ilçeden (Aladă̆, Ceyhan, Çukurova, Feke, İmamoğlu, Pozantı, Karaisalı, Karataş, Kozan, Saimbeyli, Sarıçam, Seyhan, Yumurtalık ve Yüreğir), Mersin İli ise 13 ilçeden (Akdeniz, Aydıncık, Bozyazı, Gülnar, Mut, Yenişehir, Silifke, Erdemli, Toroslar, Mezitli, Tarsus, Anamur ve Çamlıyayla) oluşmaktadır.

\subsubsection{Hayvan ve Kümes Sayılarının Varlığı}

Adana ve Mersin ilçelerine ait hayvan ve kümes sayıları sırası ile Şekil 1 ve Şekil 2'de verilmiştir. Adana'da toplam 135 adet etlik piliç üretimi yapan işletme bulunmaktadır. Bu işletmelerde 356 adet kümes ve 6.976 .340 adet hayvan bulunmaktadır. İlçeler bazında hayvan varlığı incelendiğinde, birinci sırayı Ceyhan $(\% 25,0)$ alırken, bunu Yüreğir $(\% 21,4)$ ve Seyhan $(\% 20,8)$ ilçeleri izlemiştir. Diğer deyişle Adana ilinde yetiştiriciliğin Ceyhan, Yüreğir, Seyhan, Sarıçam, Karaisalı ve Çukurova ilçelerinde daha yoğun olarak yapıldığı görülmektedir. Mersin'de ise etlik piliç yetiştiriciliği yapan işletmelerin sayısı 756 adet olup, bu işletmelerdeki kümes sayısı 988 adet ve hayvan varlığı 15.370 .407 adettir. İlçeler bazında hayvan varlığının dağılımı ise ildeki toplam hayvan sayısının \%72,7'sini Tarsus oluştururken bunu \%9,9'la Akdeniz ve \%5,2'le Çamlıyayla izlemiştir. $\mathrm{Bu}$ ilde yetiştiriciliğin Tarsus ilçelerinde yoğunlaştığını, Aydıncık, Bozyazı ve Anamur ilçelerinde ise yetiştiriciliğin yapılmadığı ve geriye kalan ilçelerde ise son dönemlerde örtü altı yetiştiriciliğin cazibesini kaybetmesinden dolayı bölgedeki çiftçiler etlik piliç üretimine yönelmiştir. 
Adana ve Mersin'de Bulunan Etlik Piliç Kümeslerinde Oluşan Gübrenin Biyogaz ve Elektrik Üretim Potansiyelinin Belirlenmesi

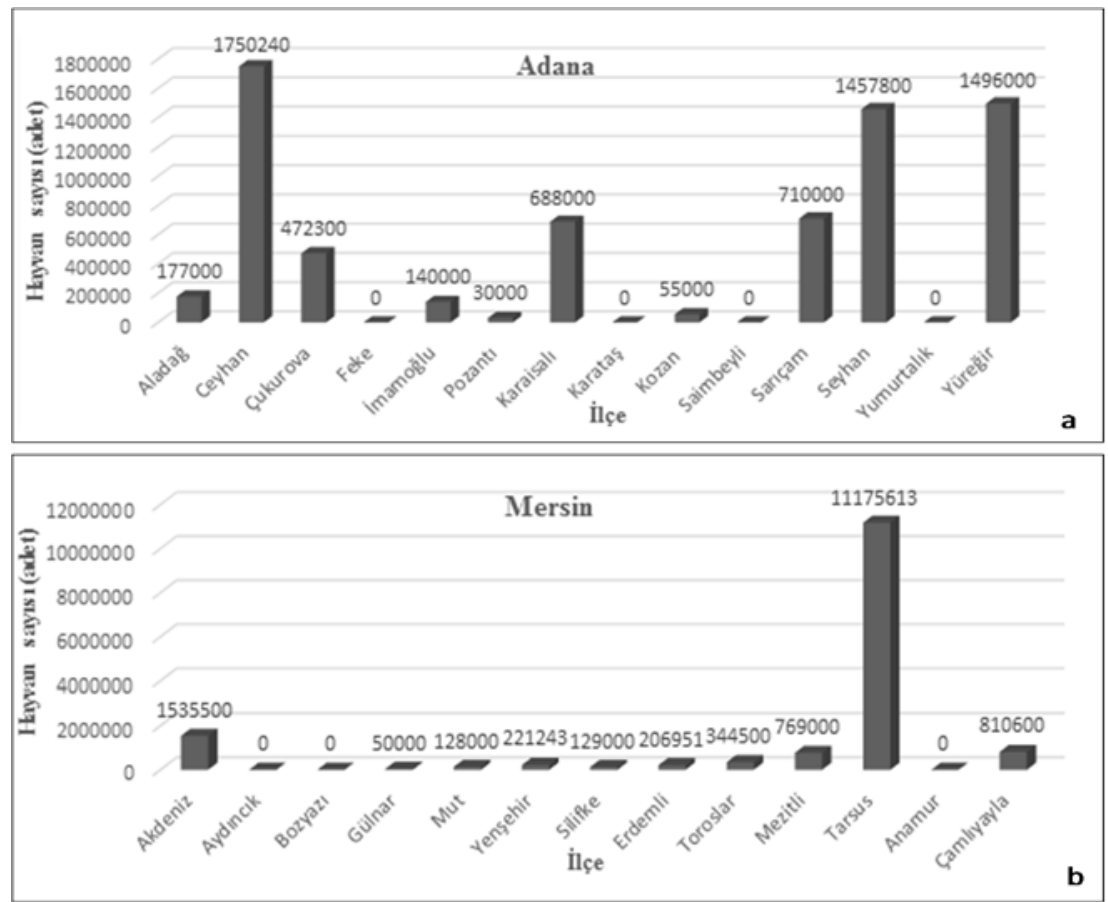

Şekil 1. Adana (a) ve Mersin (b)'in ilçe bazında hayvan sayıları
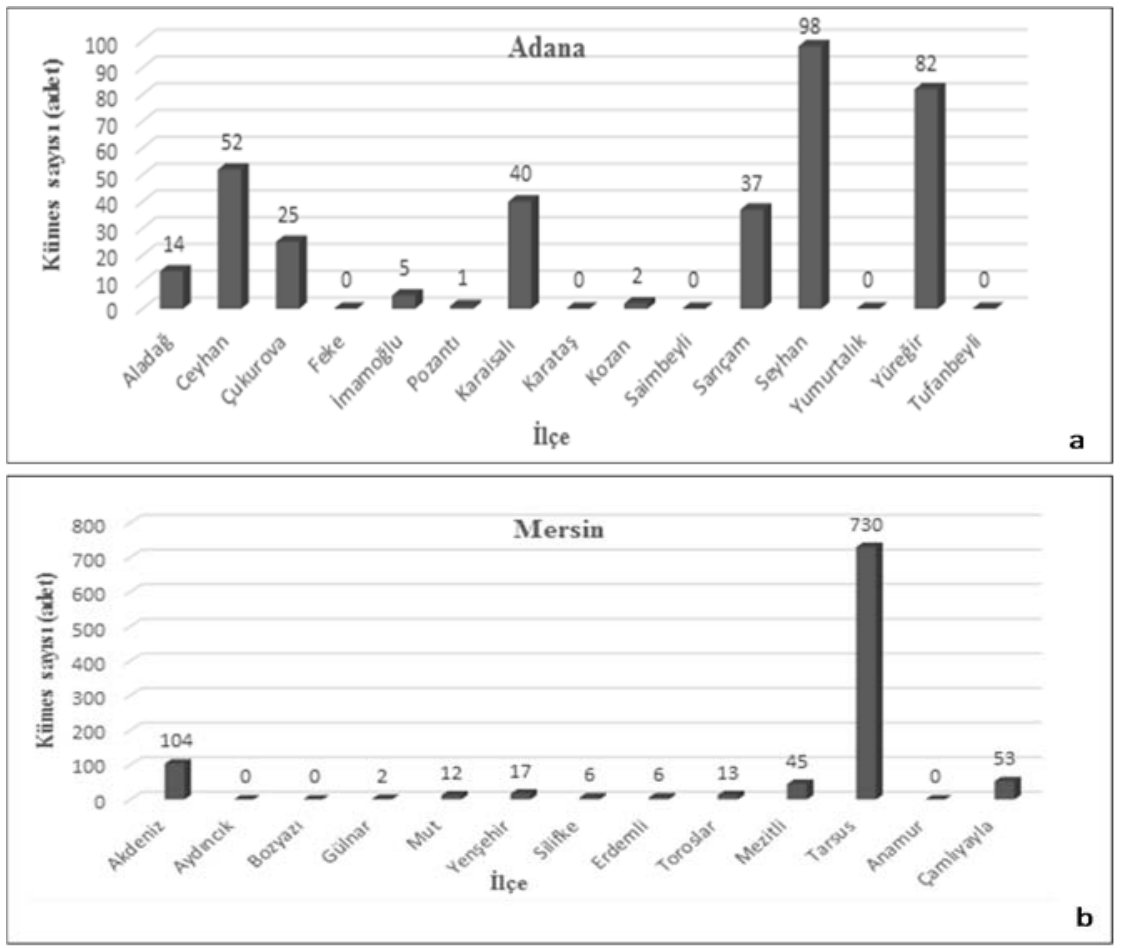

Şekil 2. Adana (a) ve Mersin (b)'in ilçe bazında kümes sayıları 


\subsection{Yöntem}

\subsubsection{Gübre ve Belirlenmesi}

\section{Biyogaz}

Miktarının

İlçelerdeki etlik piliç işletmelerinin gübre miktarlarının hesaplanmasında, çalışmada belirtilmiş olan güncel hayvan sayıları dikkate alınmıştır. Hayvan gübresi ve biyogaz üretim miktarlarının hesaplanmasında aşağıdaki eşitlikler kullanılmıştır;

$\mathrm{GM}=(\mathrm{HS} * \mathrm{GGM} * \mathrm{AK} * 365) / 1000$

Eşitlikte 1'de;

GM, yıllık gübre miktarı (ton/y1l)

GGM, günlük gübre üretimi (kg/gün-hayvan)

AK, atığın kullanılabilirliği (\%)

$\mathrm{KM}=\mathrm{GM} * \mathrm{KMO}$

Eşitlik 2'de;

KM, yıllık kuru madde miktarı (ton/yıl)

KMO, kuru madde oranı (\%)

$\mathrm{UKM}=\mathrm{KM} * \mathrm{UKMO}$

Eşitlik 3'de;

UKM, yıllık uçucu madde miktarı (ton/yıl)

UKMO, uçucu kuru madde oranı (\%)

$\mathrm{BM}=(\mathrm{UKM} *$ ÖMÜ) $* 1000$
Eşitlik 4'de;

$\mathrm{BM}$, yıllık biyogaz üretim miktarı $\left(\mathrm{m}^{3} / \mathrm{y} 1 \mathrm{l}\right)$

ÖMÜ, özgül biyogaz(metan) üretimi $\left(\mathrm{m}^{3} \mathrm{CH}_{4} / \mathrm{kg}\right.$ UKM)

$\mathrm{TID}=(\mathrm{BM} * \mathrm{BID}) * 1000$

Eşitlik 5'de;

TID, yıllık toplam ısıl değeri (GJ/yıl)

BID, biyogazın birim isıl değeri $\left(\mathrm{MJ} / \mathrm{m}^{3}\right)$

$\mathrm{EÜ}=(\mathrm{TID} * \mathrm{EÜV}) / 3,6$

Eşitlik 6'da;

EÜ, yıllık elektrik üretimi $\left(\mathrm{MW}_{\mathrm{he}} / \mathrm{y} 1 \mathrm{l}\right)$

EÜV, gaz motorunun net elektrik üretim verimi $(\%)$

Hesaplamalarda gübre miktarı, kuru madde miktarı, uçucu madde miktarı ve biyogaz üretim potansiyeline ilişkin yapılan kabuller Çizelge 1'de özetlenmiştir. Biyogazın \%60 metan içeriğindeki enerji değeri $22,7 \mathrm{MJ} / \mathrm{m}^{3}$ [12] olduğundan, $1 \mathrm{~m}^{3}$ metan gazının enerji değeri $36 \mathrm{MJ}$ alınarak biyogazın enerji potansiyel değerleri hesaplanmıștır. Çalışmada biyogaz amaçlı kullanılabilecek etlik piliç gübresi, hayvanların barınakta kalma süreleri dikkate alınarak atığın kullanılabilirliği \%99 olarak seçilmiştir [13-15]. Adana ve Mersin'in ilçeler bazındaki hayvan sayıları verilerine göre hesaplanan yıllık yaş gübre miktarı değerleri Çizelge 2'de verilmiştir.

Çizelge 1. Etlik piliç için atık miktarı kabulleri $[13,14,16,17]$

\begin{tabular}{|l|c|}
\hline Parametreler & Alınan Değerler \\
\hline Birim hayvan için günlük gübre üretimi (kg/gün-hayvan) & 0,18 \\
\hline Atı̆̆ın kullanılabilirliği (\%) & 99,0 \\
\hline Kuru madde oranı (\%) & 25,88 \\
\hline Uçucu kuru madde oranı (\%KM) & 77,27 \\
\hline Hammadde özgül metan üretimi (m ${ }^{3} \mathrm{CH}_{4} / \mathrm{kg} \mathrm{UKM)}$ & 0,35 \\
\hline
\end{tabular}


Adana ve Mersin'de Bulunan Etlik Piliç Kümeslerinde Oluşan Gübrenin Biyogaz ve Elektrik Üretim Potansiyelinin Belirlenmesi

Çizelge 2. Adana ve Mersin'in ilçe bazlı hesaplanan yaş gübre miktarı değerleri

\begin{tabular}{|l|c|c|l|c|c|}
\hline \multicolumn{3}{|c|}{ Mersin } & \multicolumn{3}{c|}{ Adana } \\
\hline İlçeler & $\begin{array}{c}\text { GM } \\
(\mathrm{t} / \mathrm{yl} \text { l) }\end{array}$ & $\begin{array}{c}\text { İl toplamına göre oranı } \\
(\%)\end{array}$ & İlçeler & $\begin{array}{c}\text { GM } \\
(\mathrm{t} / \mathrm{yl} \mathbf{l})\end{array}$ & $\begin{array}{c}\text { İl toplamına göre oranı } \\
(\%)\end{array}$ \\
\hline Akdeniz & $99.873,53$ & 9,89 & Aladağ & $11.628,90$ & 2,54 \\
\hline Aydıncık & 0,00 & 0,00 & Ceyhan & $114.990,77$ & 25,09 \\
\hline Bozyazı & 0,00 & 0,00 & Çukurova & $31.030,11$ & 6,77 \\
\hline Gülnar & $3.285,00$ & 0,33 & Feke & 0,00 & 0,00 \\
\hline Mut & $8.409,60$ & 0,83 & İmamoğlu & $9.198,00$ & 2,01 \\
\hline Yenişehir & $14.535,67$ & 1,44 & Pozantı & $1.971,00$ & 0,43 \\
\hline Silifke & $8.475,30$ & 0,84 & Karaisalı & $45.201,60$ & 9,86 \\
\hline Erdemli & $13.596,68$ & 1,35 & Karataş & 0,00 & 0,00 \\
\hline Toroslar & $22.633,65$ & 2,24 & Kozan & $3.613,50$ & 0,79 \\
\hline Mezitli & $50.523,30$ & 5,00 & Saimbeyli & 0,00 & 0,00 \\
\hline Tarsus & $734.237,77$ & 72,71 & Sarıçam & $46.647,00$ & 10,18 \\
\hline Anamur & 0,00 & 0,00 & Seyhan & $95.777,46$ & 20,90 \\
\hline Çamlıyayla & $53.256,42$ & 5,27 & Yumurtalık & 0,00 & 0,00 \\
\hline & & & Yüreğir & $98.287,20$ & 21,44 \\
\hline & & Tufanbeyli & 0,00 & 0,00 \\
\hline Toplam & $1.009 .835,74$ & 100,00 & Toplam & $458.345,54$ & 100,00 \\
\hline
\end{tabular}

Çizelge 2'de görüldüğü üzere, Mersin İli’nde y1llık üretilen yaş gübre miktarı 1.009.835,74 ton olup, bu değerin yaklaşı \% $\% 3$ 'ü Tarsus'ta, \%10'u Akdeniz'de ve $\% 5$ 'i Mezitli'de ve \%5'i Çamlıyayla'da üretilmektedir. Tarsus ilçesinde etlik piliç yetiştiriciliğin yaygın olmasından dolayı bu ilçeden elde edilecek gübre miktarı da doğal olarak yüksek olacaktır. Bu durum Tarsus ilçesinin kırsal kesiminde bulunan kümeslerin biyokütle bakımından önemli potansiyele sahip olduğunu göstermektedir.

Adana ilindeki yıllık yaş gübre miktarı 458.345,54 ton olarak hesaplanmıștır. Hesaplanan bu gübrenin yaklaşık \%25'i Ceyhan'da, \%21'i Yüreğir'de, \%20'si Seyhan ilçelerinde bulunmaktadır. Mersin yaş gübre miktarı bakımından Adana'nın yaklaşık iki katını oluşturmaktadır (Çizelge 2).

Üretilen yaş gübre miktarları hayvan sayısına bağlı olduğundan bu sektörde yapılacak teşvik ve desteklemelerle üreticileri hem yetiştiricilik açısından daha güçlenmesine hem de atık maddelerin değerlendirilmesinde (1sı ve elektrik gibi) önemli katkısı olacaktır. Ayrıca, kümeslerin daha modern üretim modeline kavuşturularak atıkların bertaraf edilmesinde çevre ve yeraltı sularının kirlenmesi gibi olumuz etmenleri de asgari düzeye indirecektir.

Adana ve Mersin'in ilçeler bazında haritası, Arcmap 10.2 programı ile WGS 84 koordinat referans sisteminde sayısallaştırılmış ve vektör katman haline getirilmiştir. Oluşturulan ilçelerin toplam biyogaz enerji potansiyel (GJ/y1l) değerlerine göre 5 sınıf olacak şekilde QGIS 2.16.3 programı ile sınıflandırmaya tabi tutulmuş ve sınıf değerlerine göre renklendirilmiştir.

\section{BULGULAR VE TARTIŞMA}

Adana ve Mersin ilçelerinde bulunan etlik piliç işletmelerinin gübrelerinden elde edilebilir uçucu kuru madde miktarları ve bu maddelerden elde edilebilecek biyogaz ve isı enerjisi potansiyeli değerleri Çizelge 3 ve Çizelge 4'te verilmiştir.

Adana'da yaş gübreden elde edilebilecek yıllık uçucu madde miktarı 91.657,54 ton olup, bundan üretilebilecek yıllık biyogaz metan potansiyeli 32.080.138,64 $\mathrm{m}^{3}$ ve 1s1 enerji miktar1 11.760,58 GJ olarak hesaplanmıştır (Çizelge 3). $\mathrm{Bu}$ değerler Mersin İli'nde ise sirası ile 201.941,66 ton, 70.679.580,90 $\mathrm{m}^{3}$ ve 25.911,13 GJ olarak belirlenmiştir (Çizelge 4).

Adana İli'nde biyogaz metan üretim potansiyeli ilçeler bazında değerlendirildiğinde 8.048.337,93 $\mathrm{m}^{3}$ ile Ceyhan İlçesi'nin en yüksek potansiyele sahip olduğu görülmektedir. Bunu sırası ile Yüreğir $\left(6.879 .235,73 \mathrm{~m}^{3}\right)$, Seyhan $\left(6.703 .576,10 \mathrm{~m}^{3}\right)$, Sarıçam $\left(3.264 .877,92 \mathrm{~m}^{3}\right)$ ve 
Karaisalı (3.163.712,69 $\left.\mathrm{m}^{3}\right)$ izlemiştir. Geriye kalan diğer ilçelerdeki biyogaz üretim potansiyelinin ise bu ilçelere göre daha düşük düzeylerde olduğu görülmektedir. Mersin ilçelerinde bu değer incelendiğinde en yüksek potansiyele sahip ilçenin 1.584.155,55 $\mathrm{m}^{3}$ ile Tarsus olduğu belirlenmiştir. Diğer ilçeler ise Tarsus'un sahip olduğu potansiyelin yanında çok düşük değerlerde kalmıştır.
Biyogazın gaz motorunda yakıt olarak kullanılmasıyla üretilecek yıllık elektrik enerjisi miktarı Mersin ve Adana illerinde sirası ile 2.879.01 MWhe ve 1.306,73 MWhe olarak hesaplanmıştır. İlçeler bazında yapılan hesaplamalarda ise, Mersin'in Tarsus İlçesi'nde üretilebilecek yıllık elektrik enerjisi üretiminin 2.093,29 MW'la en yüksek değerde olduğu belirlenmiștir. Bunu 284,74 MW'la Akdeniz ve 151,83 MW'la Çamllyayla izlemiştir (Çizelge 3-4).

Çizelge 3. Adana'nın ilçeler bazında etlik piliç gübresi kuru madde, uçucu kuru madde, metan ve enerji değerleri

\begin{tabular}{|l|c|c|c|c|c|}
\hline \multicolumn{1}{|c|}{ İlçeler } & $\begin{array}{c}\text { KM } \\
(\mathrm{t} / \mathrm{y} 1 \mathrm{l})\end{array}$ & $\begin{array}{c}\text { UKM } \\
(\mathrm{t} / \mathrm{y} 1)\end{array}$ & $\begin{array}{c}\mathrm{BM} \\
\left(\mathrm{m}^{3} / \mathrm{y} 1 \mathrm{l}\right)\end{array}$ & $\begin{array}{c}\text { TID } \\
(\mathrm{GJ} / \mathrm{y} 1 \mathrm{l})\end{array}$ & $\begin{array}{c}\text { EÜ } \\
(\mathrm{MWh} / \mathrm{y} 1 \mathrm{l})\end{array}$ \\
\hline Aladağ & $3.009,56$ & $2.325,49$ & $813.920,27$ & 298,38 & 33,15 \\
\hline Ceyhan & $29.759,61$ & $22.995,25$ & $8.048 .337,93$ & $2.950,52$ & 327,84 \\
\hline Çukurova & $8.030,59$ & $6.205,24$ & $2.171 .833,58$ & 796,19 & 88,47 \\
\hline Feke & 0,00 & 0,00 & 0,00 & 0,00 & 0,00 \\
\hline İmamoğlu & $2.380,44$ & $1.839,37$ & $643.778,74$ & 236,01 & 26,22 \\
\hline Pozantı & 510,09 & 394,15 & $137.952,59$ & 50,57 & 5,62 \\
\hline Karaisalı & $11.698,17$ & $9.039,18$ & $3.163 .712,69$ & $1.159,82$ & 128,87 \\
\hline Karataş & 0,00 & 0,00 & 0,00 & 0,00 & 0,00 \\
\hline Kozan & 935,17 & 722,61 & $252.913,08$ & 92,72 & 10,30 \\
\hline Saimbeyli & 0,00 & 0,00 & 0,00 & 0,00 & 0,00 \\
\hline Sarıçam & $12.072,24$ & $9.328,22$ & $3.264 .877,92$ & $1.196,90$ & 132,99 \\
\hline Seyhan & $24.787,21$ & $19.153,07$ & $6.703 .576,10$ & $2.457,53$ & 273,06 \\
\hline Yumurtalık & 0,00 & 0,00 & 0,00 & 0,00 & 0,00 \\
\hline Yüreğir & 25.436 .73 & $19.654,96$ & $6.879 .235,73$ & $2.521,93$ & 280,21 \\
\hline Tufanbeyli & 0,00 & 0,00 & 0,00 & 0,00 & 0,00 \\
\hline Toplam & $118.619,83$ & $91.657,54$ & $32.080 .138,64$ & $11.760,58$ & $1.306,73$ \\
\hline
\end{tabular}

Çizelge 4. Mersin'in ilçeler bazında etlik piliç gübresi kuru madde, uçucu kuru madde, metan ve enerji değerleri

\begin{tabular}{|l|c|c|c|c|c|}
\hline \multicolumn{1}{|c|}{ İlçeler } & $\begin{array}{c}\text { KM } \\
(\mathrm{t} / \mathrm{yll})\end{array}$ & $\begin{array}{c}\text { UKM } \\
(\mathrm{t} / \mathrm{y} 1 \mathrm{l})\end{array}$ & $\begin{array}{c}\mathrm{BM} \\
\left(\mathrm{m}^{3} / \mathrm{y} 1 \mathrm{l}\right)\end{array}$ & $\begin{array}{c}\text { TID } \\
(\mathrm{GJ} / \mathrm{y} \text { 1l })\end{array}$ & $\begin{array}{c}\text { EÜ } \\
(\mathrm{MWh} / \mathrm{y} 1 \mathrm{l})\end{array}$ \\
\hline Akdeniz & $25.847,27$ & $19.972,18$ & $6.990 .264,57$ & 2562,63 & 284,74 \\
\hline Aydıncık & 0,00 & 0,00 & 0,00 & 0,00 & 0,00 \\
\hline Bozyazl & 0,00 & 0,00 & 0,00 & 0,00 & 0,00 \\
\hline Gülnar & 850,16 & 656,92 & $229.920,98$ & 84,29 & 9,37 \\
\hline Mut & $2.176,40$ & $1.681,71$ & $588.597,71$ & 215,78 & 23,98 \\
\hline Yenişehir & $3.761,83$ & $2.906,77$ & $1.017 .368,15$ & 372,97 & 41,44 \\
\hline Silifke & $2.193,41$ & $1.694,85$ & $593.196,13$ & 217,47 & 24,16 \\
\hline Erdemli & $3.518,82$ & $2.718,99$ & $951.647,54$ & 348,87 & 38,76 \\
\hline Toroslar & $5.857,59$ & $4.526,16$ & $1.584 .155,55$ & 580,75 & 64,53 \\
\hline Mezitli & $13.075,43$ & $10.103,38$ & $3.536 .184,68$ & $1.296 ., 37$ & 144,04 \\
\hline Tarsus & $190.020,74$ & $146.829,02$ & $51.390 .157,93$ & $18.839,63$ & $2.093,29$ \\
\hline Anamur & 0,00 & 0,00 & 0,00 & 0,00 & 0,00 \\
\hline Çamliyayla & $13.782,76$ & $10.649,94$ & $3.727 .478,93$ & $1.366,49$ & 151,83 \\
\hline Toplam & $261.45,49$ & $201.941,66$ & $70.679 .580,90$ & $25.911,13$ & $2.879,01$ \\
\hline
\end{tabular}


Potansiyel olarak Tarsus'un tüm ilçelere göre çok avantajlı konuma sahip olduğu görülmektedir. Adana İli'nde ise ilçe bazında üretilecek elektrik enerjisi değerine bakıldığında, Ceyhan, Yüreğir, Seyhan, Sarıçam ve Karaisalı ilçelerinde potansiyel olduğu görülmektedir. Bu ilçelerdeki yıllık elektrik üretim miktarı ise sırasıly 327,84 ; $280.21 ; 273,06 ; 132,99$ ve $128,87 \mathrm{MW}_{\text {he }}$ olarak hesaplanmıştır (Şekil 3).
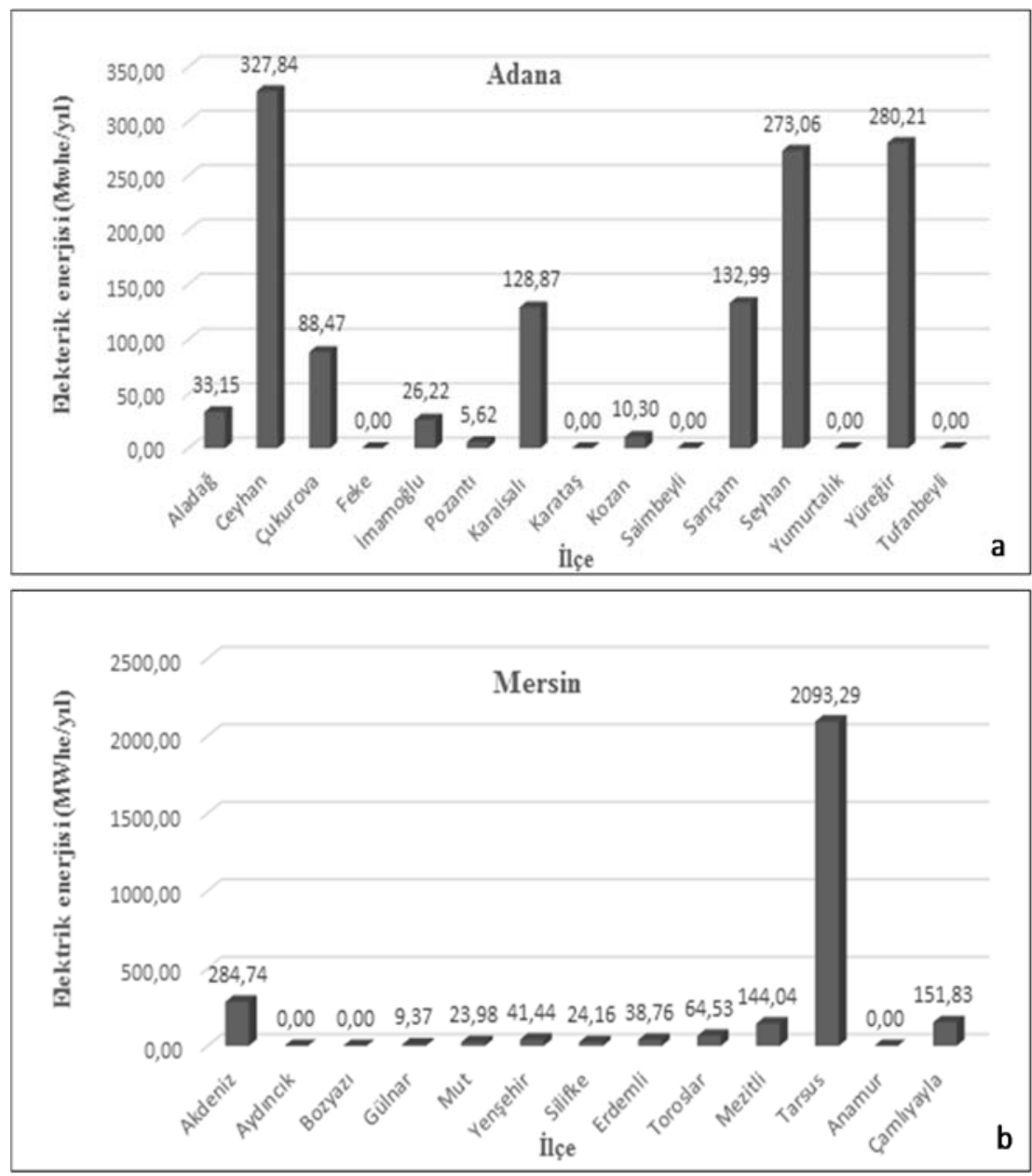

Şekil 3. Adana (a) ve Mersin (b)'in ilçeler bazında etlik piliç işletmelerinde üretilebilecek elektrik enerjisi değerleri

Ülkemizin bölgesel ve genel biyogaz üretim potansiyelini değerlendirmek için çok sayıda çalışmalar yapılmıştır. Son dönemlerde yapılan bu çalışmalardan bir kaçı aşağıdaki gibi özetlenebilir;

Çağlayan ve Koçer [8] tarafindan yapılan çalışmada Muş ilindeki küçük ve büyük baş hayvan atıklarından yılda 1.598 .960 ton yaş gübre ve bu gübreden $79.940 .328 \mathrm{~m}^{3}$ biyogaz üretebilecek potansiyele sahip olduğu hesaplanmıştır. Erensoy ve arkadaşları [18], Etlik piliç üretiminde atık materyal olarak çevresel sorunlara neden olan tavuk gübresinin biyogaz üretiminde kullanımı ve potansiyelini ortaya koymak amacıyla bir çalışma yapmışlardır. Çalışma sonucunda, 2 milyon hayvandan yıllık 
yaklaşık 432 bin ton yaş gübre elde edilebileceğini ve bu gübreden yıllık 68 milyon $\mathrm{m}^{3}$ biyogaz ve 105.699,16 MW elektrik enerjisi üretebileceğini bildirmişlerdir. Aybek ve arkadaşları [19], Kahramanmaraş İli'nin hayvansal ve bitkisel atıklarının biyogaz potansiyelini $2.177 \mathrm{TJ} / \mathrm{y} 1 \mathrm{l}$ olduğunu ve bu enerjinin yaklaşık \%95'ini hayvansal atıkların oluşturduğunu bildirmişlerdir.

Eryılmaz ve arkadaşları [20] tarafindan yapılan bir çalışmada Yozgat'ın hayvan gübresinden üretebilir biyogaz potansiyelinin 45 milyon $\mathrm{m}^{3} / \mathrm{y} 1$ l olduğu hesaplanmıştır. Karaca [17], Hatay ve ilçelerinde hayvan gübresinden (süt sığırı ve yumurta tavuğu) biyogaz potansiyelini belirlemek amaciyla yaptığ 1 çalışmada, Hatay’da biyogaz üretiminde kullanılabilecek yıllık toplam 885 bin ton yaş gübre üretilebileceği ve bu gübreden yillı 15 milyon $\mathrm{m}^{3}$ biyogaz ve $340 \mathrm{TJ}$ 1s1 enerjisi elde edilebileceğini bildirmiştir.

Seyhan ve Badem [2] tarafindan yapılan çalışmada, Erzincan İli hayvansal atıklarından elde edilebilir yıllık biyogaz miktarı $15.511 .011 \mathrm{~m}^{3}$, elektrik enerjisi $38.025 .864 \mathrm{~kW}_{\text {he }}$ ve $1 \mathrm{~s}$ enerjisi 35.818.027.112 kCal olarak hesaplanmıştır. Çalışmada Erzincan'ın biyogaz kaynaklı elektrik kurulu gücü bakımından 4,3 MW'lik bir potansiyele sahip olduğu, biyogaz ve enerji üretimi değerleri açısından da kayda değer bir nitelik taşıdığı bildirilmektedir.

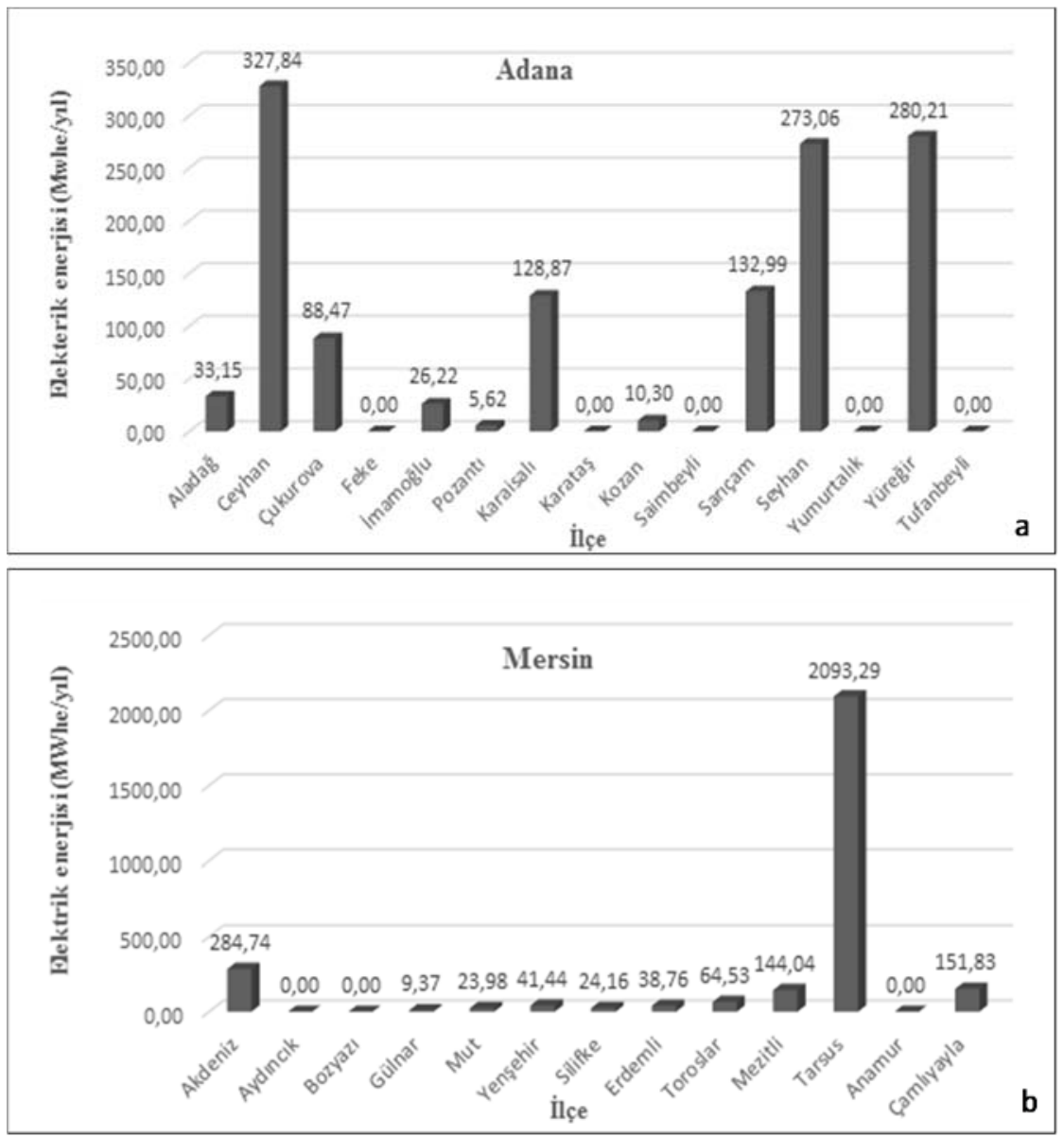

Şekil 3. Adana (a) ve Mersin (b)'in ilçeler bazında etlik piliç işletmelerinde üretilebilecek elektrik enerjisi değerleri 


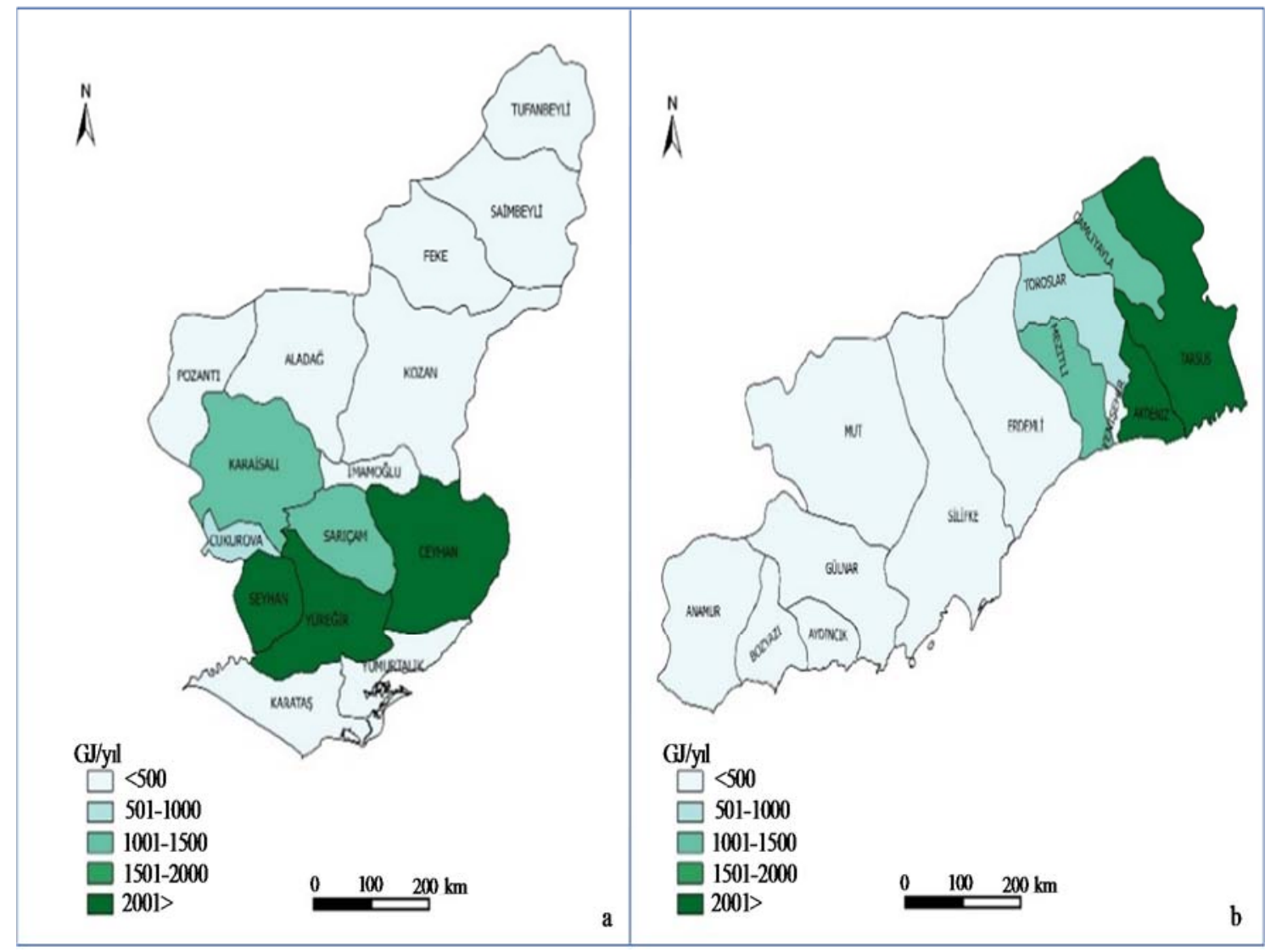

Şekil 4. Adana (a) ve Mersin (b) ilçelerine göre toplam biyogaz enerji potansiyeli

Özetlenen çalışmalardan da görüldüğü üzere atıklardan elde edilebilecek biyogaz potansiyeli hayvan sayısı, hayvan cinsi gibi birçok faktörlere bağlı değişkenlik göstermektedir. Bu nedenle, yapılan bu çalışmada bulunan sonuçların literatür ile kıyaslanması yapılmamıştır. Adana ve Mersin illerine ait ilçelerin toplam biyogaz enerji potansiyel değerlerine göre haritalanması Şekil 4'de verilmiştir.

Adana ve Mersin'in ilçelerine göre elde edilecek toplam biyogaz enerji potansiyeli (GJ/yıl) değerleri 5 sınıfa ayrılmıştır. Yapılan sınıflandırmada Adana ilinde $<500$ sınıfında Feke, Karataş, Saimbeyli, Tufanbeyli, Yumurtalı, Pozant, Kozan, İmamoğlu, Aladağ, 501-1000 sinıfinda Çukurova, 1001-1500 sınıfında Karaisalı ve Sarıçam, 2001> sınıfında Seyhan, Yüreğir, Ceyhan ilçelerinin yer aldığı görülmüştür. Mersin İli’ndeki sinıflandirma ise, $<500$ sinıfinda Aydıncık, Bozyazı, Anamur, Gülnar, Mut, Silifke, Erdemli, Yenişehir, 501-1000 sinıfinda Toroslar, 1001-1500 sınıfında Mezitli ve Çamlıyayla, 2001> sınıfında Akdeniz ve Tarsus ilçeleri yer almıştır.

Bölgede yetiştiriciliğin kırsal kesimde yapılması ve aile tipi işletme yapısında olması nedeniyle bölgedeki kümeslerin üretim kapasite dağılımının bilinmesi yerel anlamda sürdürülebilir çözümlerin üretilmesinde etkili olacaktır. Bu nedenle, Hayvan Sağlı̆̆ı ve Yetiştiriciliği Şube Müdürlüğünden alınan veriler doğrultusunda yapılan değerlendirme sonucunda bölgedeki kümeslerin yaklaşık \%78'inin 15.000-25.000 adet üretim kapasitesi aralığında değiştiği belirlenmiştir. Çalışmada, bölgeyi karakterize edecek ve kapasitesi 15-30 bin aralığında olan 3 adet kümes belirlenmiştir. Belirlenen bu kümeslerde işletme sahipleri ile 
yapılan birebir görüşmelerde ve kümeslerdeki güç kaynakları etiketinden okunan değerler Çizelge 5'de verilmiştir.

Çizelge 5'te görüldüğü üzere, üç farklı ilçede bulunan kümeslerde yapılan incelemelerde elektrik tüketim kaynaklarının toplam değeri; üretim kapasitesi (hayvan/dönem) 22.000 olan kümeste $25,8 \mathrm{~kW}, 31.000$ olan kümeste $28,6 \mathrm{~kW}$ ve $2 \times 23.000$ olan kümeste $41,6 \mathrm{~kW}$ olarak belirlenmiştir. $\mathrm{Bu}$ kümeslerde yıllık tüketilen elektrik enerjisi değeri ise sırası ile 20.316; 34.653 ve $61.662 \mathrm{kWh}$ olarak tespit edilmiştir. İşletmelerin y1llık elektrik enerjisi tüketim değerleri EnerjiSA Toroslar Elektrik Perakende Satış A.Ş'den alınmıştır. İşletme içerisinde bulunan bakıcı veya ailenin barındı ̆̆ 1 meskende tüketilen elektrik enerjisi miktarları bu enerji tüketimi içerisindedir. Dört kişilik bir ailenin asgari yaşam standartlarına göre ortalama aylık elektrik enerjisi tüketimi $221 \mathrm{kWh}$, yıllık ise $2.652 \mathrm{kWh}$ olarak değişmektedir [2,21].

Çizelge 5. Üç farklı kümesin üretim özelliği ve elektriksel kurulu güç dağılımı

\begin{tabular}{|c|c|c|c|}
\hline İşletme & Ceyhan & Tarsus & Yüreğir \\
\hline Üretim kapasitesi (hayvan/dönem) & $2 \times 23.000$ & 22.000 & 31.000 \\
\hline Y1llık üretim dönemi & 5 & 5 & 5 \\
\hline Gübre miktarı (t/yıl)) & 55 & 40 & 45 \\
\hline Isıtmada kullanılan kömür (ton/yıl)) & 30 & 7,5 & 12 \\
\hline \multicolumn{4}{|l|}{ Elektrik tüketim kaynakları $(\mathrm{kW})$} \\
\hline Aydınlatma & 1,4 & 1,1 & 1,4 \\
\hline Serinletme (Fan-Ped) & 20,9 & 18,3 & 17,6 \\
\hline Yem dağıtma & 5,5 & 3,0 & 1,7 \\
\hline Sulama & 8,8 & 2,3 & 5,2 \\
\hline Isitma & 5,0 & 1,1 & 2,7 \\
\hline Toplam & 41,6 & 25,8 & 28.6 \\
\hline Elektrik enerji tüketimi (kWh/yıl) & 61.662 & 20.316 & 34.653 \\
\hline
\end{tabular}

Çizelge 5'teki seçilen üç farklı kümesin yılda elde edilen gübre miktarları ve bu gübrelerden üretilecek biyogaz ve elektrik enerjisi değerleri Çizelge 6'da verilmiştir (Biyogaz ve elektrik enerjisi değerleri Eşitlik 6'daki hesaplama yöntemine göre yapılmıştır ve yılda 5 dönem üretim yapıldığı varsayılmıştır).

Çizelge 6. Kümes kapasitesine göre üretilebilecek metan ve elektrik enerjisi değerleri

\begin{tabular}{|l|c|c|c|c|c|}
\hline $\begin{array}{l}\text { Kümes kapasitesi } \\
\text { (adet) }\end{array}$ & $\begin{array}{c}\text { HS } \\
(\mathrm{adet})\end{array}$ & $\begin{array}{c}\text { GM } \\
(\text { ton/y1l })\end{array}$ & $\begin{array}{c}\mathrm{BM} \\
\left(\mathrm{m}^{3} / \mathrm{y} 1\right)\end{array}$ & $\begin{array}{c}\text { TID } \\
(\mathrm{GJ} / \mathrm{y} 1)\end{array}$ & $\begin{array}{c}\text { EÜ } \\
\left(\mathrm{kW}_{\mathrm{he}} / \mathrm{y} 1 \mathrm{l}\right)\end{array}$ \\
\hline 20000 & 100.000 & $6.570,00$ & $459.841,96$ & 168,58 & $18.730,90$ \\
\hline 25000 & 125.000 & $8.212,50$ & $574.802,45$ & 210,72 & $23.413,62$ \\
\hline 30000 & 150.000 & $9.855,00$ & $689.762,94$ & 252,87 & $28.096,34$ \\
\hline 45000 & 225.000 & $14.782,50$ & $1.0345 .644,41$ & 379,30 & $42.144,52$ \\
\hline
\end{tabular}

Çizelge 5 ve Çizelge 6'da görüldüğü üzere, Tarsus ilçesinde seçilen 22.000 hayvan kapasitesine sahip kümeste biyogazdan üretilecek elektrik enerjisinin bu kümesin y1llık elektrik enerji ihtiyacını karşılayabilecek potansiyele sahip olduğu tespit edilmiştir. Ceyhan ve Yüreğir ilçelerindeki kümeslerin ise elektrik enerjisini karşılayamadığı belirlenmiştir. Ancak, gübreden üretilebilecek elektrik enerjisinin Ceyhan İlçesi'ndeki kümesin elektrik enerjisinin \%68'ini, Yüreğir İlçesi'ndeki kümesin ise \%82'ini karşılayabilme potansiyeline sahip olduğu görülmektedir. Seçilen kümeslerde serinletme sistemini oluşturan fanların güç değerleri, kümesin toplam elektrik tüketim kaynakları değerinin yaklaşık \%50-71'ni oluşturmaktadır (Çizelge 5). Bu da gösteriyor ki, 
biyogazdan üretilecek elektrik enerjisi üretiminin kümeste aydınlatma, ısıtma, su ve gübre dağıtımı gibi küçük ölçekli elektrik motorların enerji gereksinimini karşılayabilecektir. Ayrıca, bölgedeki işletmelerde bulunan aile fertlerinin ısınma ve aydınlatma gibi evin temel elektrik tüketimini de sağlayabilecektir.

Adana ve Mersin illerini kapsayan Çukurova bölgesinde yaz aylarında hava sicaklığ $40^{\circ} \mathrm{C}$ 'ye kadar ulaşmaktadır. $\mathrm{Bu}$ nedenle bölgede özellikle Haziran-Ekim ayları arasında kümeste hayvanların gereksinim duyduğu optimum çevre koşullarını sağlamak için serinletme sistemleri (fanlar) gecegündüz sürekli çalışmaktadır. Buda, işletmelerin bu dönemlerdeki elektrik enerjisi tüketimini önemli oranda yükseltmektedir. Kümes sahipleriyle yüz yüze yapılan görüşmelerde yaz döneminde elektrik faturalarının çok yüksek geldiğini ve bununda üretim girdisini önemli oranda yükselttiğini dolayısıyla, bu dönemlerde ekonomik olarak olumsuz etkilendiklerini ifade etmişlerdir.

Tarsus ilçesindeki kümeslerin yıllık elektrik tüketiminin gübreden elde edilebilecek enerji potansiyeline sahip olmasının nedeni, bu bölgede bulunan kümeslerin çoğunun rakım düzeyinin yüksek olduğu (Toros dağlarının eteği kesiminde, yayla kesiminde) bölgelerde bulunduğundan hava sıcaklığının yaz döneminde ovaya göre serin geçtiğinden dolayı serinletme sistemlerinin daha az devreye girmesinden kaynaklandığı düşünülmektedir.

Erensoy ve arkadaşları [18], 25.000 hayvan kapasitelik bir etlik piliç kümesinden her dönemde 54 ton yaş gübre elde edildiğini ve bu gübreden elde üretilecek biyogaz miktarının $85.104 \mathrm{~m}^{3}$ ve elektrik enerjisinin $13.191,12 \mathrm{~kW}_{\text {he }}$ olduğunu ve yıllık 79.146,72 $\mathrm{kW}_{\mathrm{he}}$ 'llk elektrik üretilebileceği bildirilmiştir. $\mathrm{Bu}$ değerlere göre, Ceyhan, Yüreğir ve Tarsus ilçelerinde seçilen kümeslerin yıllık elektrik enerjisi ihtiyacını karşılayabilecek potansiyele sahip olduğu söylenebilir. Günümüzde birçok ülkede biyogazın ekonomik ve çevresel önemi benimsenmiş ve uygulamaları başlatılmıştır. Ülkemizde ise bu uygulamaların henüz beklenen düzeye gelmediği görülmektedir. Konuya ilişkin yapılacak araştırma ve uygulamalar ile yeni teknolojilerin gelişimine katkılar sağlayacağı unutulmamalıdır.

Ülkemizde iller bazında kurulmuş biyogaz tesislerinin kapasitesine göre dağılımları aşağıda gibi özetlenebilir;

Biyogaz tesisleri olarak 5 adet $15 \mathrm{~m}^{3}$ 'lük ve 2 adet $22 \mathrm{~m}^{3}$ 'lük tesis Kayseri'de, $15 \mathrm{~m}^{3}$ 'lük 1 adet Konya'da, $22 \mathrm{~m}^{3}$ 'lük 1 adet Gediz gölcük köyünde ve $280 \mathrm{~m}^{3}$ 'lük 1 adet Elazığ'da bulunmaktadır. Ayrıca, Ankara'nın Beypazarı İlçesine kurulan bir biyogaz tesisinde tavuk gübresi kullanarak metan biyogaz üretmeye başlanmıştır. Kurulan tesiste saatte 2,5 MW elektrik enerjisi üretilmiştir. $\mathrm{Bu}$ üretimin yanında 1 sı ve organik gübre üretildiği belirtilmiştir [4].

\section{SONUÇ VE ÖNERÍLER}

Adana ve Mersin ilçelerinde bulunan etlik piliç kümeslerindeki gübrelerin biyogaz enerjisi potansiyelinin belirlenmesi amaciyla yapilan bu çalışmada elde edilen sonuç ve öneriler aşağıdaki gibi özetlenebilir;

Adana ilinin etlik piliç gübresinden yıllık üretilebilecek biyogaz metan potansiyeli $32.080 .138,64 \mathrm{~m}^{3}$, 1s1 enerji miktar1 11.760,58 GJ ve elektrik enerjisi miktarı 1.306,73 $\mathrm{MW}_{\text {he }}$ olarak hesaplanmıştır. $\mathrm{Bu}$ değerler Mersin ilinde ise sırası ile $70.679 .580,90 \mathrm{~m}^{3}, 25.911,13 \mathrm{GJ}$ ve $2.879,01$ $\mathrm{MW}_{\text {he }}$ olarak belirlenmiştir.

Mersin'de yaş gübreden elde edebilecek yıllık elektrik enerjisi üretiminin ilçeler bazında yapılan hesaplamalarda, 2.093,29 $\mathrm{MW}_{\text {he }}$ 'la Tarsus'un en yüksek değerde olduğu belirlenmiştir. Bunu 284,74 $\mathrm{MW}_{\text {he' }}$ 'la Akdeniz ve 151,83 $\mathrm{MW}_{\text {he' }}$ la Çamlıyayla izlemiştir. Adana ilçelerinde ise, bu değer 327,84 $\mathrm{MW}_{\text {he }}$ 'la Ceyhan, 280,21 $\mathrm{MW}_{\text {he' }}$ 'la Yüregir, 273,06 $\mathrm{MW}_{\text {he }}$ 'la Seyhan, 132,99 $\mathrm{MW}_{\text {he }}$ 'la Sarıçam ve $128,87 \quad \mathrm{MW}_{\text {he }}$ 'la Karaisalı sıralanmıştır.

Adana ve Mersin ilçelerinde etlik piliç üretimi çoğunlukla kırsal kesimde yapıldığından, 
yetiştiricilerin çoğunluğu geçim kaynağını bu sektörden sağlamaktadırlar. Son dönemlerde elektrik enerji fiyatlarında meydana gelen artışlar, üretim giderlerinin önemli ölçüde artmasına neden olmuştur. $\mathrm{Bu}$ durum, bölgedeki yetiştiricilerin rekabet gücünü zayıflatmıştır. $\mathrm{Bu}$ nedenle, Bölgede özellikle Tarsus başta olmak üzere Ceyhan, Yüreğir, Seyhan, Sarıçam ve Karaisalı ilçelerinde belirlenen bu biyogaz potansiyelinin en kısa sürede değerlendirilmesi için, bölgeye uygun alternatif projelerin üretilmesi gerekmektedir. Yapılacak projelerde üreticilere biyogaz tesisinin kazanımları hakkında teknik bilgilerin verilmesi ve tesisin kurulumu için özendirilecek teşviklerin sunulması etkili olabilecektir. Ayrıca, biyogaz tesisinin kurulumunun önemli bir yatırım giderini oluşturduğundan yetiştiricilerin önündeki bu sorunların aşılması durumunda enerjinin geri kazanımı ve çevresel risklerin azaltılması ile sektöre ve bölge sanayisine teknolojik açıdan önemli kazanımlar da sağlanabilecektir. Yapılan bu çalışmanın, etlik piliç kümeslerinde biyogaz tesislerinin planlanmasında çalışacak uzmanlara yol gösterici bir rehber olabileceği düşünülmektedir.

\section{KAYNAKLAR}

1. Abdeshahian. P., Lim, J.S., Ho, W.S, Hashim, H., Lee, C.T., 2016. Potential of Biogas Production from Farm Animal Waste in Malaysi, Renewable and Sustainable Energy Reviews, 60, 714-723.

2. Seyhan, A. K., Badem, A., 2018. Erzincan İlindeki Hayvansal Atıkların Biyogaz Potansiyelinin Araştırılması, APJES 6-1 25-35 Doi: 10.21541/apjes.334256.

3. Kaya, D., Çağman, S., Eyidoğan, M., Aydöner, C., Çoban, V., Tırıs, M., 2009. Türkiye'nin Hayvansal Atık Kaynaklı Biyogaz Enerjisi ve Ekonomisi, Atık Teknolojileri Dergisi, 1, 48-51.

4. Şenol, H., Elibol, E.A., Açıkel, Ü., Şenol, M., 2017. Biyogaz Üretimi İçin Ankara’nın Başlıca Organik Atık Kaynakları, BEÜ Fen Bilimleri Dergisi, 6 (2), 15-28.

5. Ardıç, İ, Taner, F., 2014. Biokütleden Biyogaz Üretimi I. Anaerobik Arıtımın Temelleri, http://www.emo.org.tr/ekler/14101ec47c52b48 ek.pdf (Erişim: 03.12. 2018).

6. Yenilmez, F., 2015. Tavukçuluk Atıklarından Biyogaz Üretimi, Fırat Üniversitesi Sağlık Bilimleri Veteriner Dergisi, 29(3), 205-212, http://veteriner.fusabil.org/text.php3?id=1063 (Erişim: 15.12.2018).

7. Aybek, A, Üçok, S, İspir, S., Bilgili, M. E., 2015. Türkiye'de Kullanılabilir Hayvansal Gübre ve Tahıl Sap Atıklarının Biyogaz ve Enerji Potansiyelinin Belirlenerek Sayısal Haritalarının Oluşturulması, Tekirdağ Ziraat Fakültesi Dergisi, 12(3), 109-120.

8. Çă̆layan, G.H., Koçer, N. N., 2014. Muş İlinde Hayvan Potansiyelinin Değerlendirilerek Biyogaz Üretiminin Araştırılması, Muş Alparslan Üniversitesi Fen Bilimleri Dergisi, 2, 215-220.

9. Öztürk, M., Yüksel, Y. E., 2016. Energy Structure of Turkey for Sustainable Development, Renewable and Sustainable Energy Reviews, 53, 1259-1272.

10. Özer, B., 2017. Biogas Energy Opportunity of Ardahan City of Turkey, Energy (Oxford), 139,1144-1152.

https://www.cabdirect.org/cabdirect/abstract/20 173368800.(Erişim:28.12.2018).

11. TUİK, 2017. Türkiye İstatistik Kurumu, Konularına Göre İstatistikler, Tarım. http://www.tuik.gov.tr/UstMenu.do?metod=kat egori st (Erişim: 27.11.2018).

12. Acaroğlu, M., 2007. Alternatif Enerji Kaynakları, Nobel Yayın No:1253, 90s, Ankara.

13. Külcü, R., 2007. Bazı Tarımsal Atıkların Kompostlaştırılmasında Optimum Çevresel Şartların Belirlenmesi, Yüksek Lisans Tezi, Akdeniz Üniversitesi Fen Bilimleri Enstitüsü, Tarım Makinaları Anabilim Dalı, Antalya.

14. Ekinci, K. Külcü, R, Kaya, D, Yaldız, O, Ertekin, C, Öztürk, H., 2010. The Prospective of Potential Biogas Plants that can Utilize Animal Manure in Turkey, Energy Exploration \& Exploitation, 28(3), 187-206.

15. Avcioğlu, O.A., Eliçin, A., Konuralp, A., 2010. Ankara'nın Hayvansal Atıklardan Biyogaz Potansiyeli ve Uygun Reaktör Büyüklüğünün Belirlenmesi, 26. Tarımsal Mekanizasyon 
Ulusal Kongresi, Bildiri Kitabı, 22-23 Eylül, Hatay, 356-362.

16. Hill, D.T., 1982. A Comprehensive Dynamic Model for Animal Waste Methanogenesis, Transactions of the ASAE 25(5), 1374-1380.

17. Karaca, C., 2017. Hatay İli’nin Hayvansal Gübre Kaynağından Üretilebilir Biyogaz Potansiyelinin Belirlenmesi, Mustafa Kemal Üniversitesi Ziraat Fakültesi Dergisi, 22(1), 34-39.

18. Erensoy, K., Bayraktar, H., Altan, A., 2016. Etlik Piliç Gübresinden Biyogaz ve Elektrik Üretim Potansiyeli Üzerine Bir Araştırma, https://www.researchgate.net/publication/3090 81321_Etlik_Pilic_Gubresinden_Biyogaz_ve Elektrik_Uretim_Potansiyeli (Erişim:15.12. 2018).

19. Aybek, A., Üçok, S., Bilgili, M. E., İspir, M. A., 2015. Kahramanmaraş İlinde Bazı Tarımsal Atıkların Biyogaz Enerji Potansiyelinin Belirlenerek Sayısal Haritalarının Oluşturulması. Uludağ Üniversitesi, Ziraat Fakültesi Dergisi, 29 (2), 25-37.

20. Eryilmaz, T., Yesilyurt, M.K., Gokdogan, O., Yumak, B., 2015. Determination of Biogas Potential from Animal Waste in Turkey: A Case Study for Yozgat Province, European Journal of Science and Technology, 2(4), 106-111.

21. Yiğit, F., Kabul, A., 2014. Isparta Yöresinde Bir Evin Elektrik İhtiyacının Rüzgar Enerjisi ile Karşılanmasının Ekonomik Analizi, Makine Teknolojileri Elektronik Dergisi, 11(2), 1-9. 